\title{
Health Risk, Functional Markers and Cognitive Status in Institutionalized Older Adults: A Longitudinal Study
}

Raquel Pedrero-Chamizo ( $\square$ raquel.pedrero@upm.es )

Universidad Politécnica de Madrid. Faculty of Physical Activity and Sport Sciences-INEF https://orcid.org/0000-0002-3866-4692

Ulrike Albers

ImFINE Research Group. Department of Health and Human Performance. Faculty of Physical Activity and Sport Sciences-INEF. Universidad Politécnica de Madrid

\section{Gonzalo Palacios}

ImFINE Research Group. Department of Health and Human Performance. Faculty of Physical Activity and Sport Sciences-INEF. Universidad Politécnica de Madrid

Klaus Pietrik

Department of Nutrition and Food Sciencie. Rheinische Friedrich-Wilhelms-Universitat Bonn

Agustín Meléndez

ImFINE Research Group. Department of Health and Human Performance. Faculty of Physical Activity and Sport Sciences-INEF. Universidad Politécnica de Madrid.

\section{Marcela González-Gross}

ImFINE Research Group. Department of Health and Human Performance. Faculty of Physical Activity and Sport Sciences-INEF. Universidad Politécnica de Madrid.

\section{Research}

Keywords: cardiovascular biomarkers, cognitive function, functional capacity, muscle strength, older adults, geriatrics

Posted Date: July 23rd, 2020

DOI: https://doi.org/10.21203/rs.3.rs-46731/v1

License: @ (i) This work is licensed under a Creative Commons Attribution 4.0 International License. Read Full License 


\section{Abstract \\ Background}

Follow-up of vitamin B12 and lipids status is essential in older people, being closely related to non-communicable diseases. Their relationships with cognitive and physical status are not clear. The purpose of this study was to analyze the evolution of vitamin B12 and related parameters, lipid and hematological profiles, and their relationships with cognitive and physical status among institutionalized elderly.

\section{Methods}

Sixty residents (68\% women), ranged from 62 to 99 years (mean age $85.1 \pm 5.5$ and $80.6 \pm 9.9$ years for women and men, respectively) were recruited from three nursing homes in Madrid Community (Spain). Biomarkers (vitamin B12 and related parameters, lipid and hematological profiles), functional capacity (handgrip, arm and leg strength), and cognitive status (Mini-Mental State Examination) were evaluated four times at 3-month intervals.

\section{Results}

At the beginning of the study, $63 \%$ and $70 \%$ of the sample showed abnormal homocysteine and folate values, respectively. At the end of the year, abnormal homocysteine increased to $68 \%$, abnormal folate values decreased to $50 \%$. Throughout the year, serum folate showed a significant increase (14.9 vs. $16.3 \mathrm{nmol} / \mathrm{L}),(p<0.05)$. Serum cobalamin (299 vs. $273 \mathrm{pmol} / \mathrm{L})$. HDL-cholesterol (49.9 vs. $47.0 \mathrm{mg} / \mathrm{dL})$ and triglyceride levels (102.4 vs. $123.2 \mathrm{mg} / \mathrm{dL})$ showed a significant decrease and increase respectively in mean values (all $p<0.05$ ). Serum cobalamin and HDL-cholesterol were the most important biomarkers associated with cognitive function (both $p<0.05$ ). The most relevant biomarkers associated with poor physical strength depending on the body part analyzed were low concentrations of HDL-cholesterol, LDL-cholesterol, apolipoprotein A1, and albumin (all $p<0.05)$.

\section{Conclusions}

The evolution of lipid biomarkers, their significance with cognitive values, and association with handgrip, point to the importance of the handgrip measurement, a very simple test, as an important health marker. Both serum albumin and physical strength are important health markers in older people.

\section{Introduction}

According to a new United Nations report, the world population is expected to increase by 2 billion persons, from 7.7 billion to 9.7 billion in the next 30 years [1]. The percentage of people aged (60 years or older) with respect to the total population increased from $9 \%$ in 1994 to $12 \%$ in 2014 , and in 2050 it will probably reach $21 \%$ [2].

Aging is a multifactorial process, influenced by the passage of time and by functional, physiological, biological and social changes [3]. As age increases, limitations due to health conditions become more apparent causing increasing disability, and consequently, a reduction in self-perceived quality of life. Disability is present in less than 1 in 10 people up to 44 years, compared to more than 5 in 10 among those over 74 years. But it is in the group of 85 years and more where disability is more widespread [4].

Gerontology is broadening its perspective from a prior preoccupation with disease and disability to a more comprehensive view that includes successful aging, and maintaining and improving the quality of life, is one of the main challenges posed by the aging process [4-6]. Successful aging is defined as including three main components: low probability of disease and disease-related disability, high cognitive and functional capacity, and active engagement with life. Low probability of disease refers not only to absence or presence of disease itself, but also to the absence, presence or severity of its risk factors. High functional levels include both physical and cognitive components which tell us what a person can do [5].

Two families of biomarkers are usually used to monitor the health of older people assessing cardiovascular risk factors, those related to lipids (totalcholesterol, HDL-cholesterol, LDL-cholesterol, triglycerides, apolipoprotein A1, apolipoprotein B) [7]; and those related to vitamin B12 status (serum cobalamin, holo-transcobalamin, serum and red blood cell folate, and homocysteine) [8].

The Mini-Mental State Examination (MMSE) [9] is the most widely used standardized tool for measuring cognitive impairment in clinical practice and research. Muscle weakness, a risk factor for falls, sarcopenia, and frailty, has been evaluated by several tests of muscular strength [10].

However, studies reporting results simultaneously from both types of biomarkers, muscular strength and MMSE and their evolution are scarce, especially for seniors living in homes for older adults. The purpose of this study was to investigate the evolution and relationship among these parameters over one year, in institutionalized older adults.

\section{Materials And Methods Study population}

The study was performed in the framework of a broader project dealing with the early diagnosis and treatment of vitamin B12 deficiency in Spanish older adults of both sexes [11]. Participants were recruited from three nursing homes in the Madrid Region (Spain). The study was performed with the participation 
of the responsible physician from each residence. The study design was prospective longitudinal with a one-year follow-up. Inclusion criteria were to be institutionalized older adults aged 60 or above.

Exclusion criteria were cobalamin or folate supplement intake, neuropathy, diagnosed severe dementia, Hunter's glossitis, and any disease that might prevent normal execution of most of the physical tests. Data on medication intake (for chronic as well as acute diseases) was collected from the data management systems of the nursing homes [12]. The concomitant intake of medication known to affect cobalamin absorption (such as metformin, $\mathrm{H} 2$-antagonists, and

proton pump inhibitors) was not an exclusion criterion if the medication had been started at least three months before the study and was taken continuously by the study participant for its whole duration. Furthermore, splitting the whole study population into two groups (taking or not taking medication with a possible influence on vitamin B12 status) did not result in statistical differences [13]. The study was conducted in accordance with the ethical principles of the Helsinki Declaration of 1964 and later amendments, with the Convention on Human Rights and Biomedicine of Oviedo in 1997 and approved by the Human Research Review Committee of the University of Granada. A written informed consent was obtained from all study participants and/or family representatives or guardians.

\section{Blood sampling}

Blood was collected from the participants after an overnight fast, four times over a total of one year (at month 1, 5, 9 and 13). Blood specimens were collected in Vacutainer tubes containing EDTA or gel for serum. The EDTA tubes were used for whole blood count and red blood cell folate (RBC folate) and the gel tubes were immediately placed on ice. After blood clotting, they were centrifuged at $3000 \mathrm{~g}$, aliquoted for serum samples and frozen at $-86^{\circ} \mathrm{C}$ until analysis.

\section{Biomarker measurements}

Serum cobalamin (sCbl) concentrations were measured with a Microparticle Enzyme Immunoassay (MEIA; Abbott AxSYM, Abbott Park, USA, total CV < 11\%) [13], holotranscobalamin (holoTC) by a two-step sandwich MEIA (Abbott AxSYM, total CV < 10\%) [14], serum folate and RBC folate with an ion-capture immunoassay (ICIA; Abbott AxSYM, total CV < 19\%) [15], serum total homocysteine (tHcy) with a fluorescence polarization immunoassay (FPIA; Abbott AxSYM, total CV <6\%) [16]. Analyses were performed in the biochemical laboratory of the Faculty of Sport Sciences, UPM, Madrid (Registered Lab number 242, Red de Laboratorios de la Comunidad de Madrid).

Total-cholesterol, HDL-cholesterol, LDL-cholesterol, triglycerides, apolipoprotein A1 (ApoA), apolipoprotein B (ApoB), lipoprotein A (LpA), glucose, albumin, and creatinine were obtained by standard spectrophotometric assays on a Hitachi 912 (Roche Diagnostics, Mannheim, Germany) conducted by a local certified clinical chemistry laboratory (CLIMESA, Gabinete Médico Conde-Duque, Madrid, Spain). For both biomarker families, cut-offs for abnormal values were those used routinely in each laboratory and are indicated in the footnotes of Table 2. 
Table 2

Biomarkers and functional and cognitive tests evolution along a year.

Month 1

Median
Month 5

Median IQR Mean \% (SD)

\section{Month 9}

Median IQR Mean \% abnormal
(SD)
Parameters related

to $\mathrm{B} 12$ status

\begin{tabular}{|c|c|c|c|c|c|c|c|c|c|c|c|c|}
\hline $\begin{array}{l}\text { Serum cobalamine, } \\
\mathrm{pmol} / \mathrm{L}\end{array}$ & 286 & $\begin{array}{l}231- \\
349\end{array}$ & $299(127)$ & 10 & 275 & $\begin{array}{l}223- \\
347\end{array}$ & $\begin{array}{l}293 \\
(109)\end{array}$ & 5 & 252 & $\begin{array}{l}203- \\
325\end{array}$ & $\begin{array}{l}280 \\
(134)\end{array}$ & 10 \\
\hline $\begin{array}{l}\text { Serum folate, } \\
\mathrm{nmol} / \mathrm{L}\end{array}$ & 14.0 & $\begin{array}{l}11.0- \\
16.6\end{array}$ & $14.9(5.3)$ & 70 & 15.2 & $\begin{array}{l}11.8- \\
21.5\end{array}$ & $\begin{array}{l}17.0 \\
(7.2)\end{array}$ & 55 & 15.4 & $\begin{array}{l}12.2- \\
21.5\end{array}$ & $\begin{array}{l}17.3 \\
(7.4)\end{array}$ & 53 \\
\hline $\mathrm{RBC}$ folate, $\mathrm{nmol} / \mathrm{L}$ & 779 & $\begin{array}{l}619- \\
1003\end{array}$ & $849(300)$ & 3 & 852 & $\begin{array}{l}654- \\
1102\end{array}$ & $\begin{array}{l}916 \\
(399)\end{array}$ & 4 & 872.5 & $\begin{array}{l}631.0- \\
1108.6\end{array}$ & $\begin{array}{l}956 \\
(458)\end{array}$ & 8 \\
\hline $\begin{array}{l}\text { Holotranscobalamin, } \\
\mathrm{pmol} / \mathrm{L}\end{array}$ & 46.0 & $\begin{array}{l}30.9- \\
57.3\end{array}$ & $51.8(41.3)$ & 32 & 46.2 & $\begin{array}{l}35.6- \\
65.5\end{array}$ & $\begin{array}{l}54.2 \\
(33.0)\end{array}$ & 25 & 42.8 & $\begin{array}{l}34.3^{-} \\
56.6\end{array}$ & $\begin{array}{l}53.5 \\
(38.8)\end{array}$ & 28 \\
\hline $\begin{array}{l}\text { Homocysteine, } \\
\mu \mathrm{mol} / \mathrm{L}\end{array}$ & 17.1 & $\begin{array}{l}13.9- \\
21.5\end{array}$ & $18.5(6.4)$ & 63 & 16.9 & $\begin{array}{l}14.7- \\
23.1\end{array}$ & $\begin{array}{l}19.0 \\
(6.4)\end{array}$ & 70 & 17.2 & $\begin{array}{l}14.1- \\
25.6\end{array}$ & $\begin{array}{l}19.9 \\
(7.8)\end{array}$ & 60 \\
\hline \multicolumn{13}{|l|}{$\begin{array}{l}\text { Parameters related } \\
\text { to lipids }\end{array}$} \\
\hline $\begin{array}{l}\text { Total cholesterol, } \\
\mathrm{mg} / \mathrm{dL}\end{array}$ & 189.0 & $\begin{array}{l}168.0- \\
203.3\end{array}$ & $\begin{array}{l}188.7 \\
(35.0)\end{array}$ & 30 & 194.5 & $\begin{array}{l}177.0- \\
213.5\end{array}$ & $\begin{array}{l}196.1 \\
(35.3)\end{array}$ & 43 & 197.0 & $\begin{array}{l}174.5- \\
216.5\end{array}$ & $\begin{array}{l}195.8 \\
(41.2)\end{array}$ & 46 \\
\hline $\begin{array}{l}\text { HDL-cholesterol, } \\
\mathrm{mg} / \mathrm{dL}\end{array}$ & 49.5 & $\begin{array}{l}41.0- \\
58.0\end{array}$ & $49.9(11.8)$ & 13 & 49.0 & $\begin{array}{l}40.7- \\
57.7\end{array}$ & $\begin{array}{l}49.6 \\
(11.6)\end{array}$ & 10 & 46.5 & $\begin{array}{l}36.0- \\
53.0\end{array}$ & $\begin{array}{l}46.4 \\
(11.4)\end{array}$ & 22 \\
\hline $\begin{array}{l}\text { LDL-cholesterol, } \\
\mathrm{mg} / \mathrm{dL}\end{array}$ & 116.1 & $\begin{array}{l}97.7- \\
137.5\end{array}$ & $\begin{array}{l}118.3 \\
(30.0)\end{array}$ & 33 & 122.3 & $\begin{array}{l}106.6- \\
142.3\end{array}$ & $\begin{array}{l}124.4 \\
(30.1)\end{array}$ & 43 & 126.0 & $\begin{array}{l}104.3- \\
141.4\end{array}$ & $\begin{array}{l}124.3 \\
(34.3)\end{array}$ & 46 \\
\hline Triglycerides, mg/dL & 92.0 & $\begin{array}{l}68.5- \\
121.0\end{array}$ & $\begin{array}{l}102.4 \\
(53.5)\end{array}$ & 10 & 98.0 & $\begin{array}{l}75.7- \\
128.2\end{array}$ & $\begin{array}{l}110.0 \\
(52.9)\end{array}$ & 10 & 110.0 & $\begin{array}{l}87.5- \\
138.0\end{array}$ & $\begin{array}{l}125.6 \\
(58.6)\end{array}$ & 20 \\
\hline $\begin{array}{l}\text { Apolipoprotein A1, } \\
\text { mg/dL }\end{array}$ & 132.5 & $\begin{array}{l}106.8- \\
153.3\end{array}$ & $\begin{array}{l}132.9 \\
(28.9)\end{array}$ & $\begin{array}{l}17 \\
/ 2\end{array}$ & 148.5 & $\begin{array}{l}129.2- \\
165.2\end{array}$ & $\begin{array}{l}147.7 \\
(27.6)\end{array}$ & $3 / 5^{2}$ & 143.0 & $\begin{array}{l}123.5- \\
168.0\end{array}$ & $\begin{array}{l}146.2 \\
(31.9)\end{array}$ & $7 / 3^{2}$ \\
\hline $\begin{array}{l}\text { Apolipoprotein B, } \\
\text { mg/dL }\end{array}$ & 87.5 & $\begin{array}{l}72.7- \\
94.0\end{array}$ & $84.3(18.2)$ & $\begin{array}{l}3 / \\
0^{2}\end{array}$ & 91.5 & $\begin{array}{l}77.7- \\
104.0\end{array}$ & $\begin{array}{l}90.5 \\
(17.4)\end{array}$ & $0 / 0^{2}$ & 96.0 & $\begin{array}{l}77.5- \\
107.0\end{array}$ & $\begin{array}{l}93.5 \\
(22.6)\end{array}$ & $3 / 2^{2}$ \\
\hline $\begin{array}{l}\text { Lipoprotein A, } \\
\mathrm{mg} / \mathrm{dL}\end{array}$ & 30.7 & $\begin{array}{l}17.9- \\
75.3\end{array}$ & $48.2(44.7)$ & 52 & 36.1 & $\begin{array}{l}19.1- \\
75.6\end{array}$ & $\begin{array}{l}53.1 \\
(43.7)\end{array}$ & 58 & 38.1 & $\begin{array}{l}20.3^{-} \\
57.7\end{array}$ & $\begin{array}{l}51.7 \\
(46.2)\end{array}$ & 58 \\
\hline \multicolumn{13}{|l|}{ Other parameters } \\
\hline Glucose, mg/dL & 96.5 & $\begin{array}{l}91.0- \\
108.3\end{array}$ & $\begin{array}{l}101.3 \\
(16.9)\end{array}$ & 38 & 102.0 & $\begin{array}{l}91.0- \\
108.5\end{array}$ & $\begin{array}{l}103.4 \\
(16.5)\end{array}$ & 53 & 96.5 & $\begin{array}{l}95.6- \\
105.0\end{array}$ & $\begin{array}{l}102.9 \\
(21.3)\end{array}$ & 37 \\
\hline Albumin, $\mathrm{g} / \mathrm{dL}$ & 4.0 & $\begin{array}{l}3.7- \\
4.3\end{array}$ & $4.0(0.4)$ & $\begin{array}{l}2 / \\
0^{2}\end{array}$ & 3.8 & $\begin{array}{l}3.7- \\
4.4\end{array}$ & $\begin{array}{l}3.9 \\
(0.3)\end{array}$ & $0 / 0^{2}$ & 4.1 & $\begin{array}{l}3.8- \\
4.4\end{array}$ & $4.1(0.4)$ & $7 / 0^{2}$ \\
\hline Creatinine, $\mu \mathrm{mol} / \mathrm{L}$ & 70.4 & $\begin{array}{l}61.6- \\
96.8\end{array}$ & $84.6(41.0)$ & 10 & 70.4 & $\begin{array}{l}61.6- \\
96.8\end{array}$ & $\begin{array}{l}79.6 \\
(35.4)\end{array}$ & 10 & 70.4 & $\begin{array}{l}52.8- \\
88.0\end{array}$ & $\begin{array}{l}88.3 \\
(46.1)\end{array}$ & 8 \\
\hline \multicolumn{13}{|l|}{ Functional tests } \\
\hline Handgrip, Kg & 10.6 & $\begin{array}{l}7.5- \\
18.6\end{array}$ & $13.5(8.5)$ & - & 11.6 & $\begin{array}{l}7.7- \\
19.3\end{array}$ & $\begin{array}{l}13.6 \\
(7.5)\end{array}$ & - & 10.7 & $\begin{array}{l}8.1- \\
18.6\end{array}$ & $\begin{array}{l}13.9 \\
(8.6)\end{array}$ & - \\
\hline Arm strength, rep & 10.0 & $5-13$ & $9.6(5.8)$ & - & 10.5 & $6-15$ & $\begin{array}{l}10.1 \\
(6.4)\end{array}$ & - & 11.5 & $6-14$ & $\begin{array}{l}10.7 \\
(6.9)\end{array}$ & - \\
\hline Leg Strength, rep & 5 & $0-8$ & $4.8(4.4)$ & - & 6 & $0-10$ & $\begin{array}{l}5.9 \\
(5.6)\end{array}$ & - & 3.5 & $0-11$ & $5.2(5.3)$ & - \\
\hline \multicolumn{13}{|l|}{ Cognitive test } \\
\hline MMSE, score & 17.5 & $\begin{array}{l}11.0- \\
23.0\end{array}$ & $17.3(7.6)$ & - & 16.0 & $\begin{array}{l}11.0- \\
24.5\end{array}$ & $\begin{array}{l}17.1 \\
(8.4)\end{array}$ & - & 17.0 & $\begin{array}{l}11.0- \\
23.0\end{array}$ & $\begin{array}{l}16.8 \\
(8.4)\end{array}$ & - \\
\hline
\end{tabular}

1 Abnormal values criteria: serum cobalamin < $148 \mathrm{pmol} / \mathrm{L}$; serum folate $<15.8 \mathrm{nmol} / \mathrm{L} ; \mathrm{RBC}$ folate $<362.4 \mathrm{nmol} / \mathrm{L}$; Holotranscobalamin < $35 \mathrm{pmol} / \mathrm{L}$; homocy HDL-cholesterol < $35 \mathrm{mg} / \mathrm{dL}$; LDL-cholesterol > $130 \mathrm{mg} / \mathrm{dL}$; triglycerides > $150 \mathrm{mg} / \mathrm{dL}$; Apolipoprotein A1 out of 101-198 mg/dL range; Apolipoprotein B out o; glucose $>100 \mathrm{mg} / \mathrm{dL}$; Albumin out of 3.3-5.0 g/dL range; ${ }^{2}$ Below / above normal range. ${ }^{3}$ Mean differences assessed using a mixed model with MMSE score variables. 
Three different muscle strength tests were used for the assessment of functional capacity. Maximal handgrip strength (HGS) was measured using a dynamometer Takei TKK 5101 (Takei Scientific Instruments, Japan), range 5-100 Kg with a precision $0.1 \mathrm{Kg}$. Participants sat with arm extended and parallel to the body, and without moving the wrist [17]. Two trials were recorded on both hands with at least 1-minute rest between them. The highest reading of each of the four trials was used for analysis.

Upper body strength was assessed with the arm curl test [18] whose aim is to do as many arm curls as possible in 30 seconds holding a $2 \mathrm{~kg}$ (women) or $4 \mathrm{~kg}$ (men) dumbbell in the hand of the dominant arm [17]. Participants performed two repetitions (5-minutes apart), and the mean of these trials was used for analysis.

Lower body strength was evaluated by the 30-s chair-stand test [18]. Briefly, participants sat on a chair and were asked to rise to a full stand and to sit down again. They repeated this cycle for 30 seconds so that the test score corresponds to the number of cycles performed during this time. The test was performed only once.

\section{Cognitive status}

The MMSE [9] is the most widely used standardized tool for measuring cognitive impairment in clinical practice and research. The original version translated to Spanish was used (PAR Inc., Florida, USA). It is composed of an 11-question measure that tests for functions including arithmetic, memory, and orientation. Total score ranges from 0 to 30, with lower values indicating greater impairment. Cognitive impairment cut-off for MMSE test was set to be below 24 [19].

\section{Statistical analysis}

To study the evolution of the means along a year, a mixed statistical model was applied. Dependent variables were MMSE and functional scores with time as the repeated and random effect, and gender as the fixed factor.

In a first approach to determine which biomarkers showed an association with these dependent variables, a Pearson's linear correlation was performed. Biomarkers that showed an individual correlation with cognitive and physical functions (muscular strength) were selected; an additional linear mixed model test was carried out, in order to eliminate confounding effects between biomarkers, by considering these functions as dependent variables, and biomarkers as covariates. Time was assessed as not having effect on either dependent variables or covariates.

In all cases, continuous variables were checked for Guassian normal distribution with the Kolmogorov-Smirnov test and whenever a normal distribution could not be achieved with raw data, logarithmic transformation was applied. Statistics SPSS 21.0 software (IBM, Chicago, IL, USA) was used to analyze data from subjects with complete biochemical, cognitive and physical data. Statistical significance was set at $p<0.05$.

\section{Results}

The study sample population was 60 (41 women-19 men) selected on the basis of the most highly fluctuant variable (HoloTC) among the main outcomes and the statistical tests used (dependent samples with four examination points). In order to achieve the study sample population size, ninety-eight participants were initially recruited. During the follow-up period, 36 participants (39\%) were lost because they moved out of the study area or died, and another two were excluded because they started folate/cobalamin supplementation during the observation period so that, finally the data of 60 participants were included for analysis. Table 1 shows the baseline (month 1) characteristics of this population.

\begin{tabular}{|c|c|}
\hline \multicolumn{2}{|l|}{ Sex } \\
\hline Men & 19 \\
\hline Women & 41 \\
\hline \multicolumn{2}{|l|}{ Age, years } \\
\hline Men & $80.6(9.9)$ \\
\hline Women & $85.1(5.5)$ \\
\hline \multicolumn{2}{|l|}{ Weight, Kg } \\
\hline Men & $70.0(11.0)$ \\
\hline Women & $59.3(5.2)$ \\
\hline \multicolumn{2}{|l|}{$\mathrm{BMI}, \mathrm{kg} / \mathrm{m}^{2}$} \\
\hline Men & $27.9(4.1)$ \\
\hline Women & $28.3(5.2)$ \\
\hline \multicolumn{2}{|c|}{ Abbreviations: $\mathrm{BMI}=$ body mass index } \\
\hline${ }^{1}$ Values are means (SD) or & \\
\hline
\end{tabular}

\section{Evolution of biomarkers and cognitive and physical tests over a year}

Page 5/11 
Table 2 summarizes the values of the continuous variables as medians (with interquartile range), means (with SD), and prevalence of abnormal values over one year. The prevalence of the tHcy value above normal values was high at month $1(63 \%)$ and continued to be elevated at the end of the study at month 13 (68\%). Serum folate (70\%) and HoloTC (32\%) deficiencies were present at the beginning of the study and a low decrease was observed a year later (50\% and $25 \%$, respectively). Prevalence of sCbl and $\mathrm{RBC}$ folate values deficiencies were $10 \%$ and $3 \%$ respectively at the beginning but RBC folate increased to $12 \%$ at the end of the study.

In spite of these prevalence variations, no significant changes were observed in the means of each biomarker along this period of time, except for sCbl in which the mean decreased, and for serum folate in which the mean increased slightly (both $p<0.05$ ).

Two biomarkers related to lipid profile worsened significantly throughout the year: mean HDL-cholesterol decreased $(p<0.05)$ while mean triglycerides showed an important increase $(p<0.001)$. The other means showed no significant differences throughout the year. The highest prevalence biomarker concentrations above reference range were observed first for LpA (52-53\%) followed by LDL-cholesterol (33-38\%) and total-cholesterol (30-38\%). The number of subjects presenting low HDL-cholesterol values increased over a year (13-22\%) while high triglyceride concentrations were found in $10 \%$ of the population at the beginning of the study and in $20 \%$ of subjects at month 13 .

Neither creatinine nor albumin or glucose showed significant differences throughout the study. Prevalence of glucose above normal range was high (around 45\%) and quite irregular, over the follow-up period. The mean of physical test results and MMSE scores did not differ significantly over the time-study period.

\section{Association between biomarkers and MMSE score}

When assessing bivariate correlation of each biomarker with cognitive status (Table 3), MMSE scores showed a significant positive correlation with sCbl, HDLcholesterol, ApoA and albumin. A significant negative correlation was obtained for LDL-cholesterol and triglycerides, and a clear negative tendency with totalcholesterol $(p=0.051)$. If biomarkers were incorporated simultaneously as covariates (Table 4$)$, only sCbl and HDL-cholesterol remained associated with cognitive status.

Table 3

Pearson's correlation coefficients (p) between biomarkers, cognitive and functional tests.

\begin{tabular}{|c|c|c|c|c|}
\hline Biomarkers & MMSE score & Handgrip strength (kg) & Leg strength (rep) & Arm strength (rep) \\
\hline Serum cobalamine, $\mathrm{pmol} / \mathrm{L}$ & 0.219 ** & 0.093 & -0.065 & 0.078 \\
\hline Holotranscobalamin & -0.070 & 0.039 & 0.060 & 0.023 \\
\hline Serum folate, $\mathrm{nmol} / \mathrm{L}$ & 0.028 & -0.048 & -0.001 & -0.001 \\
\hline $\mathrm{RBC}$ folate, $\mathrm{nmol} / \mathrm{L}$ & -0.012 & $-0.171^{*}$ & -0.084 & -0.101 \\
\hline Homocysteine, $\mu \mathrm{mol} / \mathrm{L}$ & -0.077 & -0.068 & -0.042 & -0.058 \\
\hline Creatinine, $\mu \mathrm{mol} / \mathrm{L}$ & -0.046 & 0.085 & -0.024 & 0.053 \\
\hline Triglycerides, $\mathrm{mg} / \mathrm{dL}$ & $-0.203^{* *}$ & $-0.139 *$ & 0.067 & -0.118 \\
\hline Total cholesterol, mg/dL & -0.132 & $-0.172 *$ & 0.134 & -0.054 \\
\hline LDL-cholesterol, mg/dL & $-0.153^{*}$ & $-0.162^{*}$ & 0.138 & $-0.153^{*}$ \\
\hline HDL-cholesterol, mg/dL & $0.182^{*}$ & 0.006 & 0.137 & $0.208 *$ \\
\hline Glucose, $\mathrm{mg} / \mathrm{dL}$ & -0.105 & -0.021 & -0.041 & -0.016 \\
\hline Apolipoprotein A1, mg/dL & $0.178 *$ & 0.068 & $0.243^{\star *}$ & $0.325^{\star *}$ \\
\hline Apolipoprotein B, mg/dL & -0.091 & -0.111 & $0.154^{*}$ & -0.072 \\
\hline Lipoprotein A, mg/dL & 0.107 & -0.126 & 0.018 & -0.066 \\
\hline Albumin, $\mathrm{g} / \mathrm{dL}$ & $0.277^{* *}$ & 0.180 * & 0.338 ** & $0.286 *$ \\
\hline
\end{tabular}




\begin{tabular}{|c|c|c|c|c|c|c|c|c|}
\hline \multirow[t]{2}{*}{ Covariates } & \multicolumn{2}{|c|}{ MMSE score } & \multicolumn{2}{|c|}{ Handgrip strength (kg) } & \multicolumn{2}{|c|}{ Leg strength (kg) } & \multicolumn{2}{|c|}{ Arm strength (kg) } \\
\hline & Param. & Sig. & Param. & Sig. & Param. & Sig. & Param. & Sig. \\
\hline Gender (men) ${ }^{1}$ & 7.279 & $<0.001$ & 12.949 & $<0.001$ & 1.746 & $<0.001$ & 6.636 & $<0.001$ \\
\hline Serum cobalamin, pmol/L & 0.009 & 0.011 & - & - & - & - & - & - \\
\hline HDL-cholesterol, mg/dL & 0.151 & $<0.001$ & 0.127 & $<0.001$ & - & - & - & - \\
\hline LDL-cholesterol, mg/dL & - & - & - & - & 0.026 & 0.031 & - & - \\
\hline Apolipoprotein A, mg/dL & - & - & - & - & - & - & 0.072 & $<0.001$ \\
\hline Albumin, g/dL & - & - & - & - & 3.906 & $<0.001$ & 2.039 & 0.014 \\
\hline \multicolumn{9}{|c|}{ Abbreviations: Param. = parameter estimate; Sig. = parameter significance } \\
\hline
\end{tabular}

It is important to note that although women exhibited worse MMSE score, the older age of the women acted as a confounding effect on gender differences (data not shown). In addition, subjects with sCbl deficiency at the beginning of the study showed lower MMSE scores $(p<0.001)$ and there was a worsening of the MMSE scores for the sCbl deficiency group one year later. Subjects with normal sCbl values showed similar MMSE scores at the beginning and the end of the study (data not shown).

\section{Association between biomarkers and functional tests}

When biomarkers were studied separately for correlation assessment, the three functional tests (strength) showed a significant positive correlation with albumin. Significant negative correlations with HGS were observed for RBC folate, total-cholesterol and, LDL-cholesterol, and triglycerides. LDL-cholesterol also had a significant negative association with arm strength (Table 3). Biomarkers, except HDL-cholesterol lost their association with HGS when observed as covariates. HDL-cholesterol became the sole marker presenting a positive significant association. Gender had also a strong positive influence on HGS (Table 4).

The Biomarkers showing a positive significant correlation with leg strength were ApoA, and albumin. When studying biomarkers as covariates, LDL-cholesterol and albumin showed a positive association with leg strength. Men recorded better leg strength values than women.

Finally, albumin, ApoA, and HDL-cholesterol showed individually a positive correlation with arm strength and a negative association of LDL-cholesterol with leg strength (Table 3). When studying these variables simultaneously, ApoA and albumin remained significantly and positively associated with HGS (Table 4). As for previous physical tests, men recorded better results than women.

\section{Discussion}

The importance of the present report is to study for the first time (to the best of our knowledge), the association of commonly available biomarkers related to vitamin B12 and lipid metabolism with physical strength (hand, arm and leg individually studied) and cognitive status, and their evolution in an older adult institutionalized population over one year. Significant associations found in this study between blood markers and cognitive and functional testing were slight.

\section{Evolution of biomarkers and cognitive and functional tests over a year}

The most important variations observed in this population throughout a year were sCbl and HDL-cholesterol decreases and triglycerides increase.

In general, for B12-related parameters, significant differences were only observed for sCbl and serum folate, without any difference in the percentage of cases with abnormal values. However, prevalence of tHcy above the normal values changed from $63 \%$ at month 1 to $68 \%$ at month 13 .

Serum folate and HoloTC deficiencies at month 1 (70\% and $32 \%)$, decreased unexpectedly (50\% and $20 \%$ respectively) which makes us wonder if there was a possible uncontrolled supplementation during the observation period). RBC folate deficiency (3\%) was low at the beginning and increased to $12 \%$ at the end of the study.

We found no relationship between physical strength and biomarkers related to vitamin B12. These results are slightly in disagreement with a previous longitudinal study which found no association with vitamin B12 but observed a significantly lower physical performance for women with high homocysteine levels [20].

Low HDL-cholesterol levels associated with low levels of HGS and low albumin and ApoA observed in poor leg and arm strength cases confirm their importance as health markers in the older adult. Low serum cobalamin and HDL-cholesterol levels were associated with poor cognitive function.

Two biomarkers of cardiovascular risk related to lipid profile worsened significantly throughout the year: mean HDL-cholesterol decreased $(p<0.05)$ while mean triglycerides showed an important increase $(p<0.001)$. Participants presenting low HDL-cholesterol increased from $13-22 \%$ and those experienced an increase in triglyceride levels increased from $10-20 \%$.

Page $7 / 11$ 
Neither creatinine nor albumin or glucose showed significant differences throughout the study. Prevalence of glucose above normal range was high (around $45 \%)$ and quite irregular, over the follow-up period. Mean of physical test results and MMSE scores did not differ significantly over the time-study period.

\section{Biomarkers and cognitive status}

In our study, the only biomarker related to vitamin B12 metabolism and associated with cognitive status, assessed by MMSE test, was sCbl. These results were consistent with the findings from some previous longitudinal studies, all performed in free-living older people, like in the Rotterdam Study with a followup of 2.7 years [21], the Leiden 85-Plus Study (4 years follow-up) [22], or the Chicago Health and Aging Project (6 years follow-up) [23]. On the other hand, several other studies reported a relationship between high tHcy and cognitive decline [24-27]. Differences in follow-up periods, cognitive test battery [27] or characteristics of the study population (e.g. free-living or institutionalized) $[11,12]$ could explain some of the discrepancies among the studies.

According to our results, HDL-cholesterol was the only lipid biomarker showing an independent association with cognitive function. Low values of HDLcholesterol correlated positively with poor MMSE scores. No significant differences were found for other lipids and lipoproteins. These results agreed with those obtained by other authors $[28,29]$, who found that cognitive dysfunction is associated with a progressive decline in plasma HDL-cholesterol concentrations This underscores the protective effects of increased plasma HDL-cholesterol and its role in maintaining superior cognition in longevity [30]. These positive associations demonstrate a significant role for lipid metabolism in preservation of cognitive function. Furthermore, implicating plasma HDLcholesterol levels in initial cognitive decline, as well as the aforementioned decrease in sCbl at the end of life, may lead to the development of specific strategies to prevent this unfavorable condition.

\section{Biomarkers, cognitive status, and physical strength}

As reported previously [17], the present study showed an association between physical functions and cognitive status which was maintained over time. In fact, several cross-sectional and longitudinal studies have sought relationships between HGS and cognitive status, finding that low levels of this type of strength are related to states of dementia [31-34].

Regarding biomarkers related to vitamin B12 status, only RBC folate showed a significant positive association with HGS. Triglycerides were associated with the MMSE score and HGS; total-cholesterol was associated with HGS and, also showed a probability of 0.051 and 0.064 with MMSE and leg strength, respectively. LDL-cholesterol was associated with MMSE, HGS and arm strength and showed a probability of 0.056 for leg strength. HDL-cholesterol was associated with MMSE and arm strength, and with a probability of 0.058 for leg strength. ApoA was significantly associated with MMSE, leg and arm strength. Lastly, ApoB was only significantly associated with leg strength $(p<0.05)$. If we exclude HDL-cholesterol with HGS and ApoB, it can be said that all these parameters showed significant associations or trends in significance between them.

The present study showed that low levels of albumin, ApoA, ApoB, and HDL-cholesterol were associated with poor physical strength. These results are similar to those obtained by other authors that in previous studies have demonstrated that low HDL-cholesterol levels are common in institutionalized or communitydwelling older adults with functional impairments [35-37]. Therefore, reduced HDL-cholesterol levels have been proposed as a general marker of "poor wellbeing" and reduced physical condition [38]. In older adult home residents, a combination of low HDL-cholesterol and low albumin were proposed as a mean to diagnose frailty and predicted a 2.5 to 4 -fold increase in short term mortality [39]. Low albumin levels, even within the normal range, have been independently associated with worsening of muscle strength [40]. Meanwhile, ApoB and ApoA are important predictors of cardiovascular risk and some studies have reported that they might outmatch the measurement of standard lipid parameters [41]. Our study has also shown an interesting fact. If we look at body parts separately and we apply the covariate model analysis, only high HDL-cholesterol values had a significant positive effect on HGS. A Japanese study showed that changes in HDL-cholesterol were significantly and independently associated with changes in HGS in older people [42]. On the other hand, LDL-cholesterol concentrations were associated with better leg strength, and high albumin concentrations with better strength parameters, and ApoA values with arm and leg strength testing results. This would mean that the association between biomarkers related to lipids and physical strength depends on the type of body parts analyzed.

\section{Strengths And Limitations}

Longitudinal data on older people are still scarce. In this sense, this is the first longitudinal study analyzing the association of biomarkers related to vitamin B12 and lipid metabolism with physical strength and cognitive status in an older adult institutionalized population. In addition, the tests used to assess each domain are well established and recognized. However, the present study has several limitations that must be considered, such as the small sample size and the short follow-up period. Therefore, further studies should be conducted using a longer follow-up period in order to assess the utility of these biomarkers as predictive parameters of cognitive or physical strength declines. Moreover, although MMSE is a widespread and validated screening tool for dementia, a comprehensive neuropsychological battery would be necessary to capture all detailed aspects of cognitive function. Finally, it is important to highlight the elevated number of drugs taken by the participants in our study. In a previous work using the same population, we reported that daily medication intake was five drugs per participant and some associations between drugs and blood parameters were observed [12].

\section{Conclusions}

Serum cobalamin, serum folate, HDL-cholesterol and triglyceride levels show significant differences in the average values throughout a year and, except for folate, were associated with poor cognitive function.

Regarding physical strength, low values of HDL-cholesterol were associated with low HGS. Low albumin concentrations were observed in cases of poor leg strength, and low albumin and apolipoprotein A1 values were associated with low arm strength, confirming both serum albumin and strength as important health markers in the older adult. We found no relationship between physical strength and biomarkers related to vitamin B12.

Page $8 / 11$ 
The associations of low and high HGS levels with low and high HDL-cholesterol values, as well as the significance of negative correlations of LDL-cholesterol and triglycerides with HGS and arm strength; and the significance with the cognitive results, point to the convenience of arm and leg measurement, and especially HGS assessment, a very simple test, as an important health marker.

\section{Declarations}

\section{Ethics approval and consent to participate}

The study was conducted in accordance with the ethical principles of the Helsinki Declaration of 1964 and later amendments, with the Convention on Human Rights and Biomedicine of Oviedo in 1997 and approved by the Human Research Review Committee of the University of Granada. A written informed consent was obtained from all study participants and/or family representatives or guardians.

\section{Consent for publication}

Not applicable.

\section{Availability of data and materials}

The datasets used and/or analyzed during the current study are available from the corresponding author on reasonable request.

\section{Competing interests}

The authors declare that they have no competing interests.

\section{Funding}

The study was supported by Axis-Shield Diagnostics Ltd (Oslo, Norway), Abbott Científica (Madrid, Spain), Asociación Familiares Alzheimer (AFAL, Spain) and the Spanish Ministry of Economy and Competitiveness (CIBERobn CB12/03/30038). Dr. Albers had a predoctoral grant from the Universidad Politécnica de Madrid.

\section{Authors' contributions}

MGG and AM created the study concept and designed the study. MGG, AM and UA recruited study participants. RPC, UA and GP performed data management, statistical analyses, and interpreted the results. RPC, UA and GP drafted the manuscript and provided administrative, technical, and material support. MGG, AM and KP supervised the study, revised, and approved the manuscript. All authors have critically read, reviewed, and approved the final manuscript.

\section{Acknowledgements}

The authors wish to thank Rosa Torres for the laboratory work and Laura Barrios for the statistical support.

\section{References}

1. United Nations Department of Public Information. World Population Prospects. 2019: Highlights (online). Available at: https://www.un.org/es/sections/issues-depth/population/index.html. Accessed March 10, 2020.

2. American College of. Sports M, Chodzko-Zajko WJ, Proctor DN, et al. American College of Sports Medicine position stand. Exercise and physical activity for older adults. Med Sci Sports Exerc 2009;41(7):1510-30.

3. Rosa TE, Benicio MH, Latorre Mdo R, Ramos LR. [Determinant factors of functional status among the elderly]. Rev Saude Publica. 2003;37(1):40-8.

4. Vidal Domínguez MJ. Aspectos Sociodemográficos de la Población Mayor. In Fernández Muñoz JN, editor, INFORME 2016: Las Personas Mayores en España: Datos Estadísticos Estatales y por Comunidades Autónomas. Madrid: Ministerio de Sanidad, Servicios Sociales e Igualdad. Secretaria de Estado de Servicios Sociales e Instituto de Mayores y Servicios Sociales (IMSERSO). 2016.

5. Rowe JW, Kahn RL. Successful aging Gerontologist. 1997;37(4):433-40.

6. OMS. (2018). La situación demográfica en el mundo en 2014. (online). Available at: https://www.un.org/en/development/desa/population/publications/pdf/trends/Concise\%20Report\%20on\%20the\%20World\%20Population\%20Situation\% Accessed Febreuary 8, 2020.

7. Upadhyay RK. Emerging risk biomarkers in cardiovascular diseases and disorders. J Lipids. 2015;2015:971453.

8. Mozos I, Stoian D, Luca CT. Crosstalk between Vitamins A. B12, D, K, C, and E Status and Arterial Stiffness. Dis Markers. 2017;2017:8784971.

9. Folstein MF, Folstein SE, McHugh PR. "Mini-mental state". A practical method for grading the cognitive state of patients for the clinician. J Psychiatr Res. 1975;12(3):189-98.

10. Rikli RE, Jones CJ. Development and validation of a functional fitness test for community residing older adults. J Aging Phys Act 1999; (7), $129-161$. 
11. Gonzalez-Gross M, Sola R, Albers U, et al. B-vitamins and homocysteine in Spanish institutionalized elderly. Int J Vitam Nutr Res. 2007;77(1):22-33.

12. Albers U, Palacios G, Pedrero-Chamizo R, Melendez A, Pietrzik K, Gonzalez-Gross M. [Polymedication in institutionalized elderly and its effect on vitamin B12, folate, and homocysteine levels]. Nutr Hosp. 2012;27(1):298-302.

13. Wilson DH, Yu J, Karian A, Kozlowski J, O'Reilly S. Development and multisite evaluation of an automated assay for B12 on the Abbott AxSYM analyzer. Clin Chem. 1999;45(3):428-9.

14. Brady J, Wilson L, McGregor L, Valente E, Orning L. Active B12: a rapid, automated assay for holotranscobalamin on the Abbott AxSYM analyzer. Clin Chem. 2008;54(3):567-73.

15. Smith J, Osikowicz G. Abbott AxSYM random and continuous access immunoassay system for improved workflow in the clinical laboratory. Clin Chem. 1993;39(10):2063-9.

16. Pernet $P$, Lasnier E, Vaubourdolle M. Evaluation of the AxSYM homocysteine assay and comparison with the IMx homocysteine assay. Clin Chem. 2000;46(9):1440-1.

17. Pedrero-Chamizo R, Albers U, Tobaruela JL, Melendez A, Castillo MJ, Gonzalez-Gross M. Physical strength is associated with Mini-Mental State Examination scores in Spanish institutionalized elderly. Geriatr Gerontol Int. 2013;13(4):1026-34.

18. Rikli RE, Jones C. Senior Fitness Test Manual. Champaign: Human Kinetics; 2001.

19. Blesa R, Pujol M, Aguilar M, et al. Clinical validity of the 'mini-mental state' for Spanish speaking communities. Neuropsychologia. 2001;39(11):1150-7.

20. van Schoor NM, Swart KM, Pluijm SM, et al. Cross-sectional and longitudinal association between homocysteine, vitamin B12 and physical performance in older persons. Eur J Clin Nutr. 2012;66(2):174-81.

21. Kalmijn S, Launer LJ, Lindemans J, Bots ML, Hofman A, Breteler MM. Total homocysteine and cognitive decline in a community-based sample of elderly subjects: the Rotterdam Study. Am J Epidemiol. 1999;150(3):283-9.

22. Mooijaart SP, Gussekloo J, Frolich M, et al. Homocysteine, vitamin B-12, and folic acid and the risk of cognitive decline in old age: the Leiden 85-Plus study. Am J Clin Nutr. 2005;82(4):866-71.

23. Tangney CC, Tang Y, Evans DA, Morris MC. Biochemical indicators of vitamin B12 and folate insufficiency and cognitive decline. Neurology. 2009;72(4):361-7.

24. Dufouil C, Alperovitch A, Ducros V, Tzourio C. Homocysteine, white matter hyperintensities, and cognition in healthy elderly people. Ann Neurol. 2003;53(2):214-21.

25. Baroni L, Bonetto C, Rizzo G, Bertola C, Caberlotto L, Bazzerla G. Association between cognitive impairment and vitamin B12, folate, and homocysteine status in elderly adults: a retrospective study. J Alzheimers Dis. 2019;70(2):443-53.

26. Garcia A, Haron Y, Pulman K, Hua L, Freedman M. Increases in homocysteine are related to worsening of stroop scores in healthy elderly persons: a prospective follow-up study. J Gerontol A Biol Sci Med Sci. 2004;59(12):1323-7.

27. Hooshmand B, Solomon A, Kareholt I, et al. Homocysteine and holotranscobalamin and the risk of Alzheimer disease: a longitudinal study. Neurology. 2010;75(16):1408-14.

28. van Exel E, de Craen AJ, Gussekloo J, et al. Association between high-density lipoprotein and cognitive impairment in the oldest old. Ann Neurol. 2002;51(6):716-21.

29. Svensson T, Sawada N, Mimura M, Nozaki S, Shikimoto R, Tsugane S. The association between midlife serum high-density lipoprotein and mild cognitive impairment and dementia after 19 years of follow-up. Transl Psychiatry. 2019;9(1):26.

30. Atzmon G, Gabriely I, Greiner W, Davidson D, Schechter C, Barzilai N. Plasma HDL levels highly correlate with cognitive function in exceptional longevity. J Gerontol A Biol Sci Med Sci. 2002;57(11):M712-5.

31. Alfaro-Acha A, Al Snih S, Raji MA, Kuo YF, Markides KS, Ottenbacher KJ. Handgrip strength and cognitive decline in older Mexican Americans. J Gerontol A Biol Sci Med Sci. 2006;61(8):859-65.

32. Hamer M, Chida Y. Physical activity and risk of neurodegenerative disease: a systematic review of prospective evidence. Psychol Med. $2009 ; 39(1): 3-11$.

33. Raji MA, Kuo YF, Snih SA, Markides KS, Peek MK, Ottenbacher KJ. Cognitive status, muscle strength, and subsequent disability in older Mexican Americans. J Am Geriatr Soc. 2005;53(9):1462-8.

34. Fritz NE, McCarthy CJ, Adamo DE. Handgrip strength as a means of monitoring progression of cognitive decline - A scoping review. Ageing Res Rev. 2017;35:112-23.

35. Nikkila M, Heikkinen J. High-density lipoprotein cholesterol and longevity. Age Ageing. 1990;19(2):119-24.

36. Wallace RB, Colsher PL. Blood lipid distributions in older persons. Prevalence and correlates of hyperlipidemia. Ann Epidemiol. 1992;2(1-2):15-21.

37. An KO, Kim J. Associations between handgrip strength with adverse cardiometabolic health among representative Korean adults. Int J Environ Res Public Health 2019 Dec 30;17(1):269.

38. Landi F, Russo A, Cesari M, Pahor M, Bernabei R, Onder G. HDL-cholesterol and physical performance: results from the ageing and longevity study in the sirente geographic area (ilSIRENTE Study). Age Ageing. 2007;36(5):514-20.

39. Zuliani G, Volpatol S, Romagnoni F, et al. Combined measurement of serum albumin and high-density lipoprotein cholesterol strongly predicts mortality in frail older nursing-home residents. Aging Clin Exp Res. 2004;16(6):472-5.

40. Schalk BW, Deeg DJ, Penninx BW, Bouter LM, Visser M. Serum albumin and muscle strength: a longitudinal study in older men and women. J Am Geriatr Soc. 2005;53(8):1331-8. 
41. Bruno G, Merletti F, Biggeri A, et al. Effect of age on the association of non-high-density-lipoprotein cholesterol and apolipoprotein B with cardiovascular mortality in a Mediterranean population with type 2 diabetes: the Casale Monferrato study. Diabetologia. 2006;49(5):937-44.

42. Kawamoto R, Kohara K, Katoh T, et al. Changes in oxidized low-density lipoprotein cholesterol are associated with changes in handgrip strength in Japanese community-dwelling persons. Endocrine. 2015;48(3):871-7. 